spirit, I will observe that it is also a question that readers could ask about Pollan's own work, which self-consciously tries to draft on this same authenticity to serve its intellectualism.

Tradition and authenticity are his ideal, but many of his informants aren't as pure as Pollan would like them to be. His barbecue pitmaster uses a proportion of supermarket charcoal, his artisanal baker uses some white flour, his cheesemaking microbiologist nun strikes a nuanced position on raw milk and his pickle guru makes an ersatz kimchi. When this occurs, Pollan wrestles with the issue, sometimes conceding, but often contradicting them or quoting other, more "fundamentalist", sources that call them out for their apostasy.

A scientific perspective on food makes a token appearance, and includes footnotes to papers in scientific journals (including Nature). But this is mostly for show; like most books based on traditional cooking, its explanations deviate from scientific accuracy. This book is, at its heart, about what people feel about food, rather than what science has shown to be true.

Pollan's proselytizing that we all ought to cook more can seem a bit strident given that we are living in the golden age of organic, sustainable artisanal local food. Interest in cooking has never been higher (even if many people still don't do it); indeed, that is why Pollan's previous books have been best sellers, as this one is also likely to be. In one passage he marvels that an artisanal baker sells his loaves for only 41 cents more than the giant Hostess Brands sells its Wonder Bread. The unspoken irony is that Hostess itself recently went bankrupt. Times have changed, and many parts of Cooked read like a call-to-arms for a revolution that is already well under way, thanks in part to Pollan's previous books. Cooked will add to that legacy.

Nathan Myhrvold is chief executive and founder of Intellectual Ventures. He is also the creator and co-author of the awardwinning books Modernist Cuisine and Modernist Cuisine at Home.

\title{
BIOLOGY
}

\section{Vive la différence}

\section{Suzanne Alonzo relishes a synthesis of the extraordinary variations among males and females of the same species.}

$\mathrm{F}$ Torget men and women being from different planets. In Odd Couples, Daphne Fairbairn shows that males and females of many species look almost as if they hail from different galaxies. What is a little friction over whether the toilet seat should be left up or down? You could be a female giant seadevil with a parasitic mate one-fiftieth of your size stuck to you for his entire adult life - or a male garden spider, eaten by your mate after you have broken off your genitals to ensure her fidelity.

Fairbairn, an evolutionary biologist, demonstrates that such differences between the sexes are a fundamental component of biological diversity, affecting everything from an animal's behaviour and appearance to its life expectancy and nervous system. After a general introduction to how this works, Fairbairn spends the bulk of the book on a guided tour of sexual dimorphism in eight carefully selected and researched species, covering two fishes, a bird, a mammal and four diverse invertebrates.

As Fairbairn lucidly explains, the defining distinction between the sexes is that females make eggs and males make sperm. What is harder to understand is how that - along with a species' basic biology and habitat can drive a cascade of differences in almost every aspect of male and female biology. Whether an organism makes eggs or sperm can affect, for example, the energy it takes to reproduce. This, in turn, affects how much energy each sex has left for growth and survival. Disparities in these, in their turn, alter the body size, habitat use, metabolic rate and reproductive behaviour favoured by Darwinian selection in males versus females. Over time, these effects lead to striking differences in body mass, colour and much more between males and females of the same species. It remains a challenge to understand how these myriad factors interact to shape the striking differences in what it means, across species, to be male or female.

Fairbairn's tour elucidates these points as it entertains. After first exploring the perhaps more familiar patterns found in mammals and birds (elephant seals and the great bustard, species in which males vastly outweigh, and compete for, females), we encounter much stranger creatures. Take the boneeating tubeworm: deep below the ocean's surface, harems of dwarf males live within the tube-like home of a single, much larger, female. Even more bizarre are the shell-burrowing barnacles, whose long-lived females weigh 500 times as much as the short-lived males. The males never eat, developing into little more than sperm production and delivery machines on finding a female.

A key message here is that the large, flashy males who fight one another for access to numerous small, coy females - as seen in birds and mammals - are not representative of the predominant pattern. Females are larger in $86 \%$ of animal classes with sexual size dimorphism, Fairbairn tells us, and in many species the main challenge

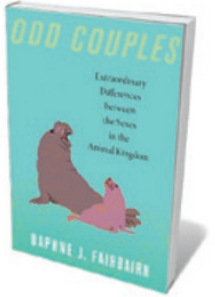

Odd Couples: Extraordinary Differences Between the Sexes in the Animal Kingdom DAPHNE J. FAIRBAIRN Princeton University Press: 2013. 312 pp. $\$ 27.95, £ 19.95$ males face is finding a female. Moreover, Fairbairn emphasizes that selection on males and females differs in a multitude of ways, rather than being primarily due to sexual selection on males (namely, competition among males for access to mates or to fertilize eggs). For example, male shellcarrying cichlid fish are much larger than females of the same species not only

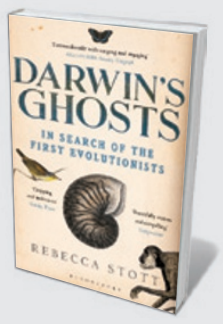

Darwin's Ghosts: In Search of the First Evolutionists Rebecca Stott (Bloomsbury, 2013; £8.99) Science historian Rebecca Stott probes the intellectual origins of the theory of natural selection, showing that Charles Darwin stood on the shoulders of giants, from Aristotle to Jean-Baptiste Lamarck. (See Andrew Berry's review: Nature $\mathbf{4 8 5}$, 171-172; 2012.)

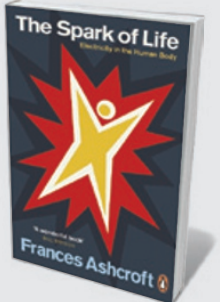

The Spark of Life: Electricity in the Human Body Frances Ashcroft (Penguin, 2013; £9.99) As you read this, ion channels regulate the electrical activity in your neurons and muscle cells. Physiologist Frances Ashcroft offers a brilliant treatment of the 'body electric', mixing research, science history and personal stories. 


\section{COMMENT SPRING BOOKS}

because reproductive competition among males for territories favours size - but also because selection favours females small enough to fit inside a shell to care for their young.

Finally, although the possible biological origins of human sex differences continue to fascinate, human sexual dimorphism is really not that striking. Men and women are boringly similar in size compared with other primates, and obviously outclassed in the oddity stakes by the other species highlighted here.

Fairbairn has simplified some material and left certain complexities out. For instance, there is nothing on the recent research documenting striking differences between the sexes in gene expression, affecting everything from early development to social behaviour, and little on the fact that we have only just begun to understand how a single genome can produce such diverse forms. But Odd Couples is a pleasure to read. There is humour (including an eyerolling joke or two), but no reliance on the anthropomorphic cuteness so common in popular books on animal behaviour - especially sexual behaviour. There are certainly moments where the author 'geeks out' on the details, and this is part of the appeal. You walk away from this book with a deeper understanding of both these creatures and a biologist's mind.

I am inevitably biased in favour of Fairbairn's theme, having spent my working life trying to understand the amazing diversity of reproductive behaviours. Even so, I found reading the book like taking a holiday in a foreign land with an enthusiastic and expert guide. You will come back with good stories, and a new appreciation of the amazing diversity of life on Earth and the forces shaping it. You may even find your perspective on bigger questions shifting.

As Fairbairn concludes: "The enduring message from all of this is that there is clearly no one way of being a male or a female." When it comes to sex roles, all bets are off in the animal kingdom.

Suzanne Alonzo is an evolutionary biologist in the Department of Ecology and Evolutionary Biology at Yale University in New Haven, Connecticut. e-mail:suzanne.alonzo@yale.edu

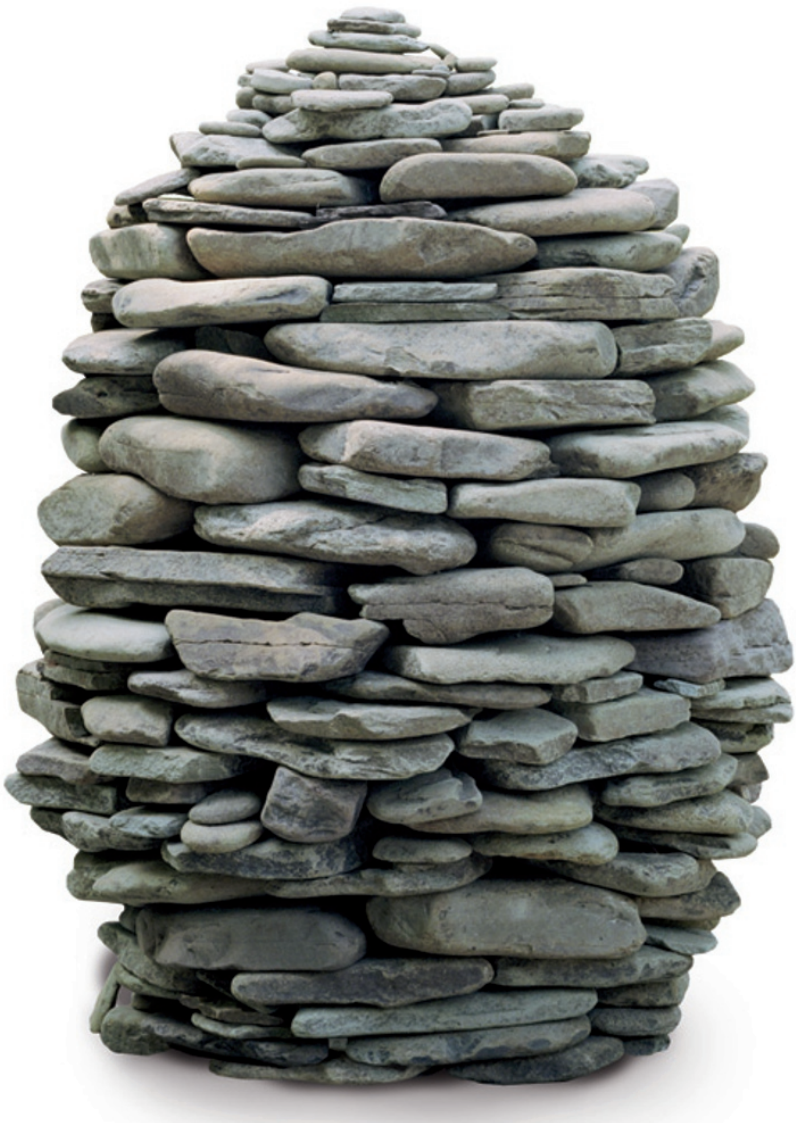

GEOLOGY

Written in stone

\section{Ted Nield relishes a deft tracing of the relationship between the rise of geology and the novel in the turbulent nineteenth century.}

$\mathrm{W}$ hen we imaginatively recreate the past, we enter a dangerous landscape: we may find ourselves needing a philosophical map. Things become even more treacherous when trying to recreate the ways our ancestors looked back at history. This entails deciphering a palimpsest. Its cartographic vagaries may further distort our hindsight. Adelene Buckland attempts just such a recreation in her book Novel Science.

Buckland tries to get inside the heads of the Britons who were writing into existence a scientific geology while developing a great literary form: the nineteenth-century novel. She succeeds triumphantly.

Like their descendants today, the groups driving these two grand projects were not much separated from each other in the late eighteenth and early nineteenth centuries. Victorian geologists, and Charles Lyell in particular, were deeply concerned with $\rightarrow$ NATURE.COM

For more on Charles

Dickens and

science, see

go.nature.com/79ckns evolving appropriate literary and visual forms that would convey their geological discoveries. The creative

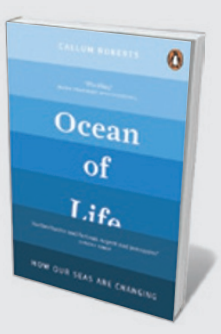

Ocean of Life: How Our Seas Are Changing Callum Roberts (Penguin, 2013; £10.99) Overfishing, acidification, plastic pollution, biogeographical shifts: marine conservation biologist Callum Roberts lucidly lays out the range of issues affecting the world's oceans. A sobering look at Earth's biggest biosphere. (See Stephen R. Palumbi's review: Nature 484, 445-446; 2012.)

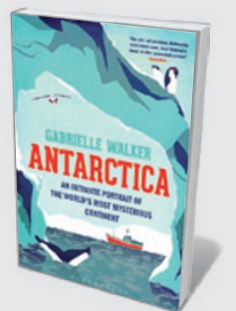

Antarctica: An Intimate Portrait of the World's Most Mysterious Continent Gabrielle Walker (Bloomsbury, 2013; £8.99) Science writer Gabrielle Walker unveils Earth's southernmost 'wild lab' in this vivid and accessible mix of researchers' stories and environmental writing. (See Francis Halzen's review: Nature 483, 272-273; 2012.) 